\title{
Pathophysiology of COVID-19 and its potential therapeutics
}

\author{
Sarfaraz Alam Khan ${ }^{1 *}$, Nazeem Ishrat Siddiqui ${ }^{2}$
}

\author{
${ }^{1}$ Department of Pharmacology, Chhindwara Institute of Medical Sciences, Chhindwara, Madhya Pradesh, India \\ ${ }^{2}$ Department of Physiology, Government Medical College, Khandwa. Madhya Pradesh, India
}

Received: 20 December 2020

Accepted: 16 January 2021

*Correspondence:

Dr. Sarfaraz Alam Khan,

Email: emailsarfaraz74@gmail.com

Copyright: (C) the author(s), publisher and licensee Medip Academy. This is an open-access article distributed under the terms of the Creative Commons Attribution Non-Commercial License, which permits unrestricted non-commercial use, distribution, and reproduction in any medium, provided the original work is properly cited.

\begin{abstract}
A series of acute and atypical serious respiratory illnesses were reported in December 2019 from Wuhan, a city of China. It spread to other places and became a global pandemic involving more than 200 countries of the world. Soon, it was discovered that this atypical respiratory illness was caused by a novel corona virus. It was named as the severe acute respiratory syndrome corona virus-2 (SARS-CoV-2) and the disease caused by it as corona virus disease-19 (COVID-19). Since COVID-19 is a new viral disease, world is still struggling to find out a permanent remedy to control this serious health problem. It seems prudent to study or have a look on the pathophysiology of SARS CoV-2 in the light of available research. Further, a review on pathophysiology may give an insight on the potential therapeutic options. Being a new virus and having potential to cause significant morbidity and mortality in short span of time various approved drugs are being repurposed for the treatment of COVID-19.
\end{abstract}

Keywords: COVID-19, Pathophysiology, Therapeutics

\section{INTRODUCTION}

A series of acute and atypical serious respiratory illnesses were reported in December 2019 from Wuhan, a city of China. It spread to other places and became a global pandemic involving more than 200 countries of the world. Soon, it was discovered that this atypical respiratory illness was caused by a novel corona virus. It was named as the severe acute respiratory syndrome corona virus-2 (SARS-CoV-2) due to its high resemblance to SARS-CoV, which was responsible for severe acute respiratory syndrome during 2002-2003 pandemic. ${ }^{1}$ Novel corona virus (SARS-CoV-2) is also called as 2019-nCoV and the disease caused by it is called as corona virus disease-19 or COVID-19. ${ }^{2}$

The coronaviruses readily evolve by mutations and have extensive animal reservoirs especially among bats. They are highly effective in host switching. ${ }^{3,4}$ SARS-CoV-2 was considered to have originated from a seafood market in
Wuhan via a zoonotic transmission. Later human to human transmission played key role in the spread of epidemic. ${ }^{5}$

Over the last two decades three novel corona viruses have crossed species barrier and caused significant morbidity and mortality in humans i.e. SARS-CoV, Middle East Respiratory Syndrome (MERS-CoV) and SARS-CoV-2. The last is the latest one and the cause of COVID-19 pandemic. ${ }^{6-8}$

Though SARS-CoV-2 primarily affects respiratory system, other organ system may also get affected. Respiratory symptoms include fever, dry cough and dyspnea. In addition, it may present as headache, dizziness, generalized weakness, vomiting and diarrhea. ${ }^{9}$, 10

Since COVID-19 is a new viral disease, world is still struggling to find out a permanent remedy to control this serious health problem. It seems prudent to study or have a look on the pathophysiology of SARS CoV-2 in the light of available research. Further, a review on 
pathophysiology may give an insight on the potential therapeutic options.

\section{BRIEF OF SARS COV-2}

\section{Type}

There are thousands of species of coronaviruses known to exist in animals. At present seven Coronaviruses are identified as human pathogens. The family of coronaviridae is divided into two subfamilies i.e. coronavirinae and torovirinae. Coronavirinae has four genera alpha, beta, gamma and delta. Alpha and beta coronavirinae infect only mammals. Gamma and delta coronaviruses infect both mammals and birds. SARS CoV2 is a beta coronavirinae. ${ }^{11,12}$

\section{Structure}

SARS CoV-2 is a single stranded, positive sense, enveloped RNA virus. It is spherical in shape and has prominent club like projections on the surface called as 'spikes'. The viral membrane has four protein structures, the spikes (S), envelop (E), membrane (M) and nucleocapscid $(\mathrm{N})$. $\mathrm{S}$ protein is a primary determinant of host and plays key role in pathogenicity. The E and $M$ proteins together form envelop and determine its shape. The hemagglutinin esterase (HE) protein may work as another cell entry mechanism for virus. The $\mathrm{N}$ protein is bound to the RNA genome and form nucleocapscid(Figure 1). ${ }^{13}$

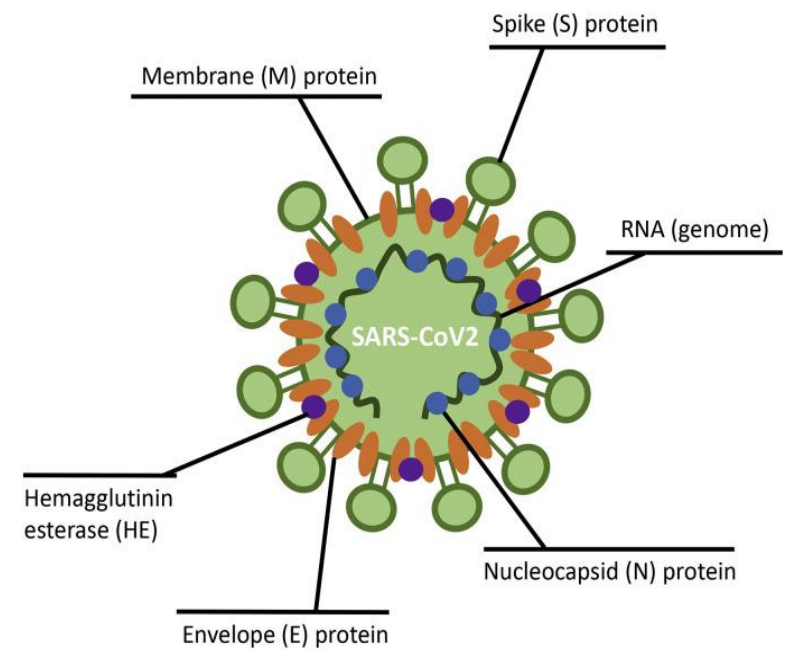

Figure 1: Structure of SARS-CoV-2.

\section{PATHOPHYSIOLOGY OF COVID-19}

Entry mechanism: Similar to SARS CoV, SARS CoV-2 use angiotensin converting enzyme receptor 2 (ACE 2) as a host cell receptor to establish infection. $S$ protein consists of S1 and S2 subunits. S1 subunit binds to host cell through receptor binding domain (RBD), thereafter S2 subunit undergoes proteolytic activation and mediates fusion between viral and the cellular membranes. ${ }^{14-16}$ ACE2 is highly expressed in alveolar cells, ciliated and goblet cells in the airway. These cells provide viruses' portal of entry in human. ${ }^{17-19}$ It explains why pneumonia is a prominent manifestation of COVID-19. ACE 2 is also expressed in intestinal epithelium, cardiac cells and vascular endothelium, which may explain gastrointestinal and cardiovascular complications of COVID-19. ${ }^{20,21}$ ACE2 is also expressed on monocytes and macrophages which may provide an entry mechanism for SARS CoV-2 into immune cells. ${ }^{22}$

Viral recognition and its evasion from immune system: At the very first step, immune cell detect viral infection through sensing virus derived pattern associated molecular pattern (PAMPs) such as viral RNA. PAMPs bind and activate pattern recognition receptors (PRRs) on immune cells resulting into immune cell activation. RNA viruses are detected by endosomal RNA PRRs including Toll-like receptors (TLR 3 and 7) and or cytoplasmic RNA sensors namely retinoic acid inducible gene I (RIG-I) and melanoma differentiation associated proteins 5 (MDA-5). Activation of these factors stimulate increased expression of type 1 interferon (TI IFN) through IFN regulatory factor (IRF 3) and other proinflammatory cytokines i.e. IL-1, IL6 , TNF $\alpha$. SARS CoV-2 evade immune system recognition by inhibiting activation of mitochondrial antiviral signaling protein.

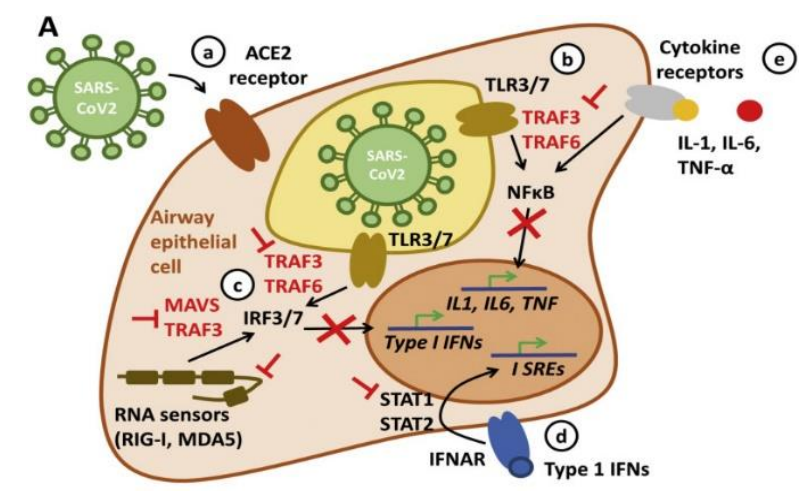

B

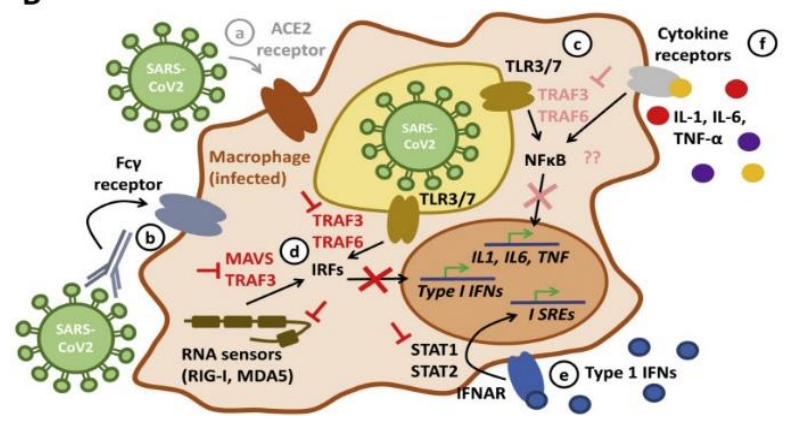

Figure 2: (A) Immune evasion strategies of SARSCoV-2. (B) Antibody directed enhancement and cytokine storm syndrome.

It also inhibits TNF receptor associated factors (TRAF) 3 and 6 , which are central for the induction of IRF $3 / 7$ in response to TLR 3/7 and or RIG-I and MDA-5. ${ }^{23,24}$ Further, novel corona viruses can inhibit T1IFN signaling 
through inhibition of STAT family transcription factor phosphorylation. In this way novel coronaviruses evade immune system and proliferate without triggering the innate antiviral responses of cells (Figure 2).

Later, infected cells die and release virus particles together with intracellular components that trigger innate inflammatory mechanism. As a result of it, adaptive immune response also get activated as a host's defense against virus. CD4+ T cell derived cytokines, CD8+ T cell mediated cytotoxicity and $\mathrm{B}$ cell mediated antibody production play important role in it. ${ }^{25}$

Humoral response: Kinetics of immune response was recently reported in a cohort study involving COVID-19 patients. The study reported median time for development of antiviral Ig $\mathrm{G}$ andIg $\mathrm{M}$ to be about 13 days after the start of symptoms, whereas all patients developed $\mathrm{IgG}$ within 19 days. However, a detailed quantifiable response in asymptomatic, mild and severe COVID-19 patients remains to be seen. ${ }^{26}$

While antibodies play important role in host defense against coronaviruses, there is a risk of antibodies triggering a harmful and exaggerated inflammatory response through a process called as antibody dependent enhancement (ADE). ${ }^{27}$ Recently a preclinical study demonstrated that antibodies against $S$ protein can activate FcYR in M2 macrophages in the lung thereby triggering an exaggerated inflammatory response with release of large quantities of IL-6 and 8, recruitment of inflammatory cells to the lung leading to acute lung injury (ALI), diffuse alveolar damage and death. ${ }^{28}$

Cytokine storm: Recent studies from Wuhan demonstrated linkage between severity of disease and unfavourable outcome with cytopenia and or significantly elevated inflammatory parameters. ${ }^{8,29}$ Enhanced innate immune activation including increase T1IFN, IL-1 $\beta$, IL-6 and TNF $\alpha$ expression centrally contributes to morbidity and mortality in COVID-19 similar to MERS and SARS. In a process referred to $\mathrm{ADE}$, virions inhibit type $1 \mathrm{IFN}$ signaling in infected macrophages while allow proinflammatory IL-1, IL-6 and TNF $\alpha$ expression, which may contribute to hyper inflammation and cytokine storm syndrome. (Figure 2) Janus kinases (JAK) are involved in cytokine receptor signaling. They mediate phosphorylation of STAT family transcription factors which are involved in pro-inflammatory cytokine expression. ${ }^{30}$

Bradykinin storm: Recently the role of bradykinin has also been proposed in COVID-19 pathology. This idea was perpetuated by the increased expression of genes for the bradykinin receptors from the lung fluid of COVID-19 patients. ${ }^{31}$ Fluid in the lung and inflammation, a key feature of COVID-19 patients, further strengthens this hypothesis. Kinin system gets activated in the back drop of blood clotting, being dysregulated in many COVID-19 patients. Bradykininand related peptides are produced through two distinct pathways: the plasma kallikrein pathway (activated by Hegeman factor, a clotting factor) and the tissue kallikrein pathway (activated by plasmin). Bradykinin is converted into des-Arg 9-bradykinin (DABK). When bradykininand DABK bind their corresponding receptors, $\mathrm{B} 2 \mathrm{R}$ andB1R respectively, fluid starts leaking from blood vessels. The Renin angiotensin system (RAS) has control over kinin system. Angiotensin converting enzyme (ACE) breaks down bradykinin while ACE2 breaks down DABK. Both ACE and ACE2 act as regulatory break over kinin system. But since ACE2 gets internalized into cell during SARS CoV-2 infection, bradykinin cascade goes into over drive. ${ }^{31,32}$

Hypercoagulability in COVID-19: Coagulopathy is a commonly reported complication in COVID-19 patients. ${ }^{33}$ The literature suggests links between RAS and coagulopathy. The Ang 1-9 peptide, that is increased in COVID-19 patients triggers thrombosis by inhibiting fibrinolysis. ${ }^{34}$ ACE increases fibrinolysis and degrades antifibrotic peptide $\mathrm{N}$-acetyl-seryl-aspartyl-lysyl-proline (AcSDKP) which is produced from thymosin beta-4. ${ }^{35}$

\section{POTENTIAL THERAPEUTIC TARGETS}

\section{Antiviral drugs}

Nucleoside analogue like remdesivir, favipiravir, geldesivir are being evaluated for treating SARS CoV-2 in clinical trials. Remdesivir, a prodrug to adenosine, compete with ATP during RNA synthesis thereby inhibiting RNA dependent RNA polymerase. It was first approved for Ebola virus infection and is under phase 3 trial in hospitalized COVID -19 patients. ${ }^{36,37}$ Favipiravir, an inhibitor of non-nucleoside RNA polymerase, was approved for treating influenza in Japan, is being under investigation for COVID-19. ${ }^{38,39}$ Galidesivir is another adenosine analogue initially developed for hepatitis C virus is also under clinical evaluation for COVID-19. ${ }^{40,41}$ Proteases are critical for viral replication as they cleave both structural and functional proteins from its precursor polypeptide. $^{42}$

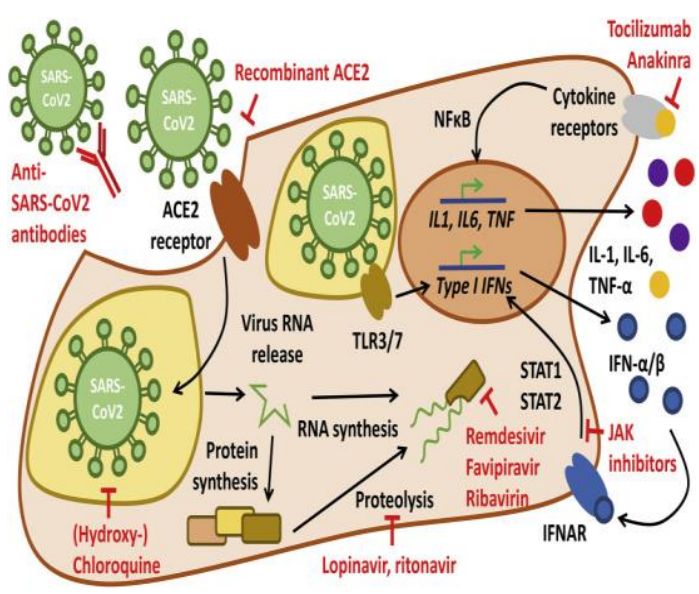

Figure 3: Potential therapeutic targets in COVID-19. 
Protease inhibitors Lopinavir/ritonavir combination has shown improved outcome in a recent clinical trial for SARS CoV-2 infection (Figure 3). ${ }^{43}$ Danoprevir, a hepatitis $\mathrm{C}$ virus protease inhibitor, is under clinicalevaluation for COVID-19. ${ }^{44}$

\section{Antimicrobial and antibiotics}

Ivermectin is a broad spectrum antiparasitic and anthelmintic agent, is being investigated for its efficacy in COVID-19 patients. ${ }^{45,46}$ Suramin sodium, which has been used to treat trypanosomiasis and onchocerciasis, has also demonstrated activity as inhibitor of reverse transcriptase enzyme of various retroviruses and growth factors. ${ }^{47}$ It is also being investigated in COVID-19 patients. $^{48}$ Azithromycin, a broad spectrum macrolide antibiotic effective against various respiratory pathogens is also being experimented as a prophylactic treatment in cancer patients undergoing chemotherapy. ${ }^{49,50}$ Doxycycline, a second generation tetracycline, has been reported to act as a potent inhibitor of dengue viral replication and diminish serum IL-6 levels at the time of infection. ${ }^{51}$ It is under phase 3 study to evaluate its efficacy in severe COVID-19 patients. $^{52}$

\section{Nonspecific anti-inflammatory and immunosuppresants}

Corticosteroids are the powerful broad spectrum antiinflammatory drugs. They have been used to treat acute respiratory distress syndrome (ARDS) because of their anti-inflammatory, antifibrotic activity and ability to prevent collagen deposition. ${ }^{53}$ Corticosteroids have been evaluated for anti-ARDS effect in COVID-19 patients without significant efficacy. ${ }^{54}$ Fingolimod is an immunomodulator of sphingosine-1-phosphate-a receptor. It has been reported to cause sequestration of lymphocytes in lymph nodes. ${ }^{55}$ It is also under investigation for COVID-19 patients. $^{56}$ Thalidomide is a known immunomodulator. It has antiangiogenesis, antifibrotic and anti-inflammatory property and is being investigated for safety and efficacy in COVID-19. ${ }^{57,58}$ Leflunomide is a FDA approved immunomodulator for treatment of rheumatoid arthritis. It inhibits dihydroorate dehydrogenase and tyrosine kinases and causes degradation of intracellular transcription factors. ${ }^{59}$ It is being investigated in ambulatory and mild COVID-19 patients. $^{60}$ Nonspecific anti-inflammatory drugs like colchicine, ibuprofen and Naproxen are also being investigated for their efficacy in COVID-19 patients. ${ }^{61-63}$

\section{Kinase inhibitors}

Janus kinase inhibitors efficiently limit cytokine expression and may help in controlling cytokine storm. (Figure 3) JAK inhibitors like jakotinib, ruxolitinib, baricitinib and tofacitinib are under various phases of clinical trial to test their efficacy and safety in severe COVID-19. ${ }^{64-67}$

\section{Monoclonal antibodies}

The blockade of cytokines during cytokine storm appears to be a more targeted approach as compared to corticosteroids and is a promising therapeutic option. Tozumabis used for treatment of bilateral lung lesions as immunotherapy, while adamumab is used in rheumatoid arthritis. ${ }^{68}$ Their combination is under evaluation for severe COVID-19 patients. ${ }^{69}$ Ravulizumab is a humanized monoclonal antibody which was first approved for paroxysmal nocturnal hemoglobinuria. It is investigated for safety and efficacy in severe COVID-19 patients. $^{70,71}$ Leronlimab is a CCR5 antagonist and significantly prevents virus entry and inhibits infection of CD4 Tcells.Leronlimab safety and efficacy in severe COVID-19 patients is under clinical trial. ${ }^{72}$ Tocilizumabis an IL-6 antagonist that selectively inhibits IL-6 mediated proinflammmatory signaling and interrupts the process of cytokine release syndrome. ${ }^{73}$ It's efficacy and safety in secondary cytokine syndrome in COVID-19 patients is under investigation (Figure 3). ${ }^{74}$

The recombinant IL-1 receptor antagonist drug anakinra was originally developed to contain cytokine syndrome in sepsis patients. It has lower risk of neutropenia and hepatotoxicity as compared to tocilizumab. ${ }^{75} \mathrm{~A}$ recent cohort study demonstrated significant efficacy of anakinra in severe COVID-19 patients. $^{76}$ Since, ACE 2 has been identified as a key molecule for cell invasion, its therapeutic blockade has been suggested to control SARS CoV 2 infection (Figure 3). A recombinant human ACE2 to neutralize virions prior to their attachment is being explored as a therapeutic option. ${ }^{77}$ As mentioned earlier, SARS CoV-2 inhibits expression of type 1 interferons resulting in exaggerated inflammatory cytokine responses and tissue damages. Recombinant interferons have been found to be effective against novel coronaviruses in in vitro studies, However clinical benefits remains to be established. $^{78}$

\section{RAS and kinin Inhibitors}

The dysfunction of the renin-angiotensin system (RAS) has been observed in coronavirus infection disease (COVID-19) patients. A recent cohort study showed improved clinical out come with RAS inhibitors in COVID-19 patients with hypertehnsion. ${ }^{79}$ Two drugs that target kinin system; icatibant (B2R blocker) and monoclonal antibody lanadelumab, which inhibit plasma Kallikrein, are under clinical trials for COVID-19 patients. $^{32}$

\section{Anticoagulants}

The scientific evidence suggests linkage between RAS and coagulopathy. The Ang 1-9 peptide that is increased in COVID-19 patients has been found to trigger thrombosis by inhibiting fibrinolysis.34 Increased fibrinolysis could therefore be achieved by increasing ACE or by 
administering thymosin beta-4 (Timbetasin), which is under investigation for COVID-19. ${ }^{31}$

\section{Convalescent plasma}

Plasma from COVID-19 recovered patients, rich in antibodies directed against SARS Co-2 is being explored as a therapeutic option. Initial results are promising in neutralizing the viral particles in the host. ${ }^{80}$

\section{Vitamins}

Vitamin C also known as ascorbic acid is popular for its antioxidant properties. It also plays important role in reducing inflammatory process, deters common cold and inhibits neutrophil accumulation in the lung. ${ }^{81,82}$ Vitamin $\mathrm{C}$ is also under clinical evaluation for its safety and efficacy in COVID-19 patients. ${ }^{83}$ Vitamin D may provide the boosting and priming effects against viral infections. Several in vitro and in vivo studies have demonstrated activity of vitamin D against acute respiratory distress syndrome and COVID-19 associated coagulopathy. ${ }^{84,85}$

\section{Limitations}

This review has tried to focus on potential therapeutic with specific target on SARS CoV-2. It may not have included all the substances under investigation as new drugs are being included in the trial or study in search of remedy on urgent basis. Information on vaccines has not been included as it requires a separate review. The review did not include special category like children and pregnant population.

\section{CONCLUSION}

The SARS COV-2 has emerged as a pandemic of potential threat of enormous magnitude to health and society with very limited success so far in terms of treatment. Being a new virus and having potential to cause significant morbidity and mortality in short span of time various approved drugs are being repurposed for the treatment of COVID-19. Targeted therapy against SARS CoV-2 remains the corner stone of treatment strategy till an effective vaccine or herd immunity is developed. This review may give an insight to researchers and treating physicians in the management of COVID-19.

\section{ACKNOWLEDGEMENTS}

The authors are thankful to the non-teaching staff of Department of pharmacology for their support.

Funding: No funding sources Conflict of interest: None declared Ethical approval: Not required

\section{REFERENCES}

1. Ksiazek TG, Erdman D, Goldsmith CS, Zaki SR, Paret $\mathrm{T}$, Emery $\mathrm{S}$ et al. A Novel coronavirus Associated with severe acute respiratory syndrome, $\mathrm{N}$ Engl J Med. 2003;348:1953-66.

2. Zhang J, Litvinova M, Wang W, Wang Y, Deng X, Chen $\mathrm{X}$ et al. Evolving epidemiology and transmission Dynamics of coronavirus disease 2019 outside Hubei provience, China: a descriptive and modelling study. Lancet Infect Dis. 2020;20(7):793-802.

3. Anthony SJ, Johnson CK, Greig DJ, Kramer S, Che X, Wells $\mathrm{H}$, et al. Global Partners in coronavirus diversity. Virus Evol 2017;3(1)vex012.

4. Johnson CK, Hitchens PL, Evans TS, Goldstein T,Thomas K, Clements A et al. Spillover and pandemic properties of zoonotic viruses with high host plasticity. Sci Rep. 2015;5:14830.

5. Li Q, Guan X, Wu P, Wang X, Zhou L, Tong Yet al. Early Transmission dynamics in Wuhan, China, of Novel Coronavirus-infected Pneumonia. N Engl J Med. 2020;382:1199-207.

6. Dorsten C, Gunther S, Preiser W, Van der Werf S, Brodt HR, Becker $S$ et al. Identification of a novel coronavirus in patients with severe acute respiratory syndrome, N Engl J Med. 2003;348(20):1967.

7. Zaki AM, Boheemen SV, Bestebroer TM, Osterhaus $\mathrm{AD}$, Fouchier RA. Isolation of a novel coronavirusfrom a men with pneumonia in Saudi Arabia. N Engl J Med 2012;367(19):1814-20.

8. Wu F, Jhao S, Yu B, Chen YM, Wang W, Song ZGet al. A new coronavirus associated with human respiratory disease in China. Nature. 2020;579 (7798): 265-9.

9. Huang C, Wang Y, Li X, Ren L, Jhao J, Hu Y at al. Clinical features of patients infected with 2019 novel coronavirus in Wuhan, China. Lancet 2020;395:497506.

10. Shi H, Han X, Jiang N, Cao Y, Alwalid O, Gu Jet al. Radiological findings from 81 patients with COVID 19 pneumonia in Wuhan, China a descriptive study. Lancet Infect Dis. 2020;20:425-34.

11. Drexler JF, Gloza-Rausch F, Glende J, Corman VM, Muth D, Goettsche Met al. Genomic characterization of severe acute respiratory syndrome - related coronavirus in European bats and classification of coronaviruses based on partial RNA-dependent RNA polymerase gene sequences. J Virol. 2010;84(21): 11336-49.

12. Drexler JF, CormanVM, Drosten C. Ecology evolution and classification of bat coronavirus in the aftermath of SARS. Antivir Res 2014;101:45-56.

13. Fehr AR, Perlman S. Coronaviruses: an overview of their replication and pathogenesis. Methods Mol Biol. 2015;1282:1-23.

14. Tortorici MA, Veesler D. Structural insights into coronavirus entry. Adv Virus Res 2019; 105: 93-116.

15. 15. Tortorici MA, Walls AC, Lang Y, Wang C, Li. Z, Koerhuis $D$ et al. Structural basis for human 
coronavirus attachment to sialic acid receptors. Nat Struct Mol Biol. 2019;26(6):481-9.

16. Walls AC, Xiong X, Park YJ, Tortorici MA, Snijder J, Quispe $\mathrm{J}$ et al. Unexpected receptor functional Mimicry Elueidates Activation of coronavirus fusion. Cell. 2019;176(5):1026-39.

17. Hamming I, Timens W, Bulthuis ML, Lely AT, Navis G, Goor HV. Tissue distribution of ACE2 Protien, the functional receptors for SARScoronavirus, A first step in understanding SARS pathogenesis. J Pathol. 2004;203(2):631-7.

18. Sims AC, Baric RS, Yount B, Burkett SE, Collins PL, pickles RJ. Severe acute respiratory syndrome coronavirus infection of human ciliated airway epithilia: role of ciliated cell in viral spread in the conducting airways of the lungs. $J$ Virol 2005;79(24):15511-24.

19. Sungnak WH, Becavin C. Berg M. HCA Lung Biological Network. SARS-cov-2 Entry Genes Are Most Highly Expressed in Nasal Goblet and Ciliated Cells within Human Airways. arXiv. 2020:2003.06122.

20. Xu H, Zhong I, Deng J, Peng J, Dan H, Zeng X et al. High exoression of ACE2 receptor of 2019-nCOV on epithelial cells of oral mucosa. Int $\mathbf{J}$ Oral Sci. 2020;12(1):9.

21. Zhang W, Zhao Y, Zhang F, Wang Q, Li T, Liu Z et al. The use of anti-in-flammatory drugs in the treatment of people with severe coronavirus disease 2019 (COVID-19): The perspectives of clinical immunologists from China. Clin Immunol. 2020;214:108393.

22. Perlman S, Dandekar AA. Immunopathogenesis of coronavirus infections: implications of SARS. Nat Rev Immunol. 2005;5(12):917-27.

23. Prompetchara E, Ketloy C, Palaga T. Immune responses in COVID-19 and potential vaccine: Lessons Learned from SARS and MERS epidemic, Asian Pac J Allergy Immunol. 2020;38(1):1-9.

24. Wit ED, Doremalen NV, Falzarano D, Munster VJ. SARS and MERS: recent insights into emerging coronaviruses. Nat Rev Microbiol. 2016;14(8):52334.

25. Yi Y, Lagniton PNP, Ye S, Li E, Xu RH. COVID-19: what has been learned and to be learned about the novel coronavirus disease. Int $\mathrm{J}$ Biol Sci. 2020;16(10):1753-66.

26. Long QX, Liu BZ, Deng HJ, Wu GC, Deng K, Chen YK et al.Antibody responses to SARS-COV-2 in patients with COVID-19. Nat Med. 2020;26(6):845-8.

27. Murrell S, Wu SC, Butler M. Review of dengue virus and the development of vaccine. Biotechnol Adv. 2011;29(2):239-47.

28. Liu L, Wei Q, Lin Q, Fang J, Wang H, Kwok H et al. Anti-spike IgG causes severe acute lung injury by skewing macrophage responses during acute SARSCoV infection. JCI Insight. 2019;4(4):e123158.

29. Chen N, Zhou M, Dong X, Qu J, Gong F, Han Y et al. Epidemiological and clinical characteristics of 99 cases of 2019 novel coronavirus pneumonia in Wuhan,
China: a descriptive study. Lancet 2020;395(10223):507-13.

30. Fu Y, Cheng Y, Wu Y. Understanding SARS-CoV-2Mediated Inflammatory Responses: From Mechanism to Potential Therapeutic Tools. Virol Sin 2020;35(3):266-71.

31. Garvin MR, Alvarez C, Miller JI, Prates TE, Walker AM, Amos BK et al. A mechanistic model and therapeutic interventions for COVID-19 involving a RAS-mediated bradykinin storm. eLife 2020;9:e59177.

32. Is a Bradykinin Storm Brewing in COVID-19? Available at: https://www.the-scientist.com/newsopinion/is-a-bradykin-storm-brewing-in-covid-1967876. Accessed on 15 th September 2020.

33. The Lancet Haematology. COVID-19 coagulopathy: an evolving story. Lancet Haematol 2020;7(6):e425.

34. Mogielnicki A, Kramkowski K, Hermanowicz JM, Leszczynska A, Przyborowski K, Buczko W. Angiotensin- (1-9) enhances stasis-induced venous thrombosis in the rat because of the impairment of fibrinolysis. Journal of the Renin-AngiotensinAldosterone System. 2014;15:13-21.

35. Kanasaki K. N-acetyl-seryl-aspartyl-lysyl-proline is a valuable endogenous antifibrotic peptide for kidney fibrosis in diabetes: an update and translational aspects. Journal of Diabetes Investigation 2020;11:516-26.

36. Scavone C, Brusco S, Bertini M, Sportiello L, Rafaniello C, Zoccoli A et al. Current pharmacological treatments for COVID-19: What's next? $\mathrm{Br} \mathrm{J}$ Pharmacol 2020;177(21):4813-24.

37. National Institutes of Health (2020). NIH clinical trial testing remdesivir plus interferon beta-1a for COVID19 treatment begins. Available at: https://www.nih.gov/ news-events/news-releases/nihclinical-trial-shows-remdesivir-acceleratesrecoveryadvanced-covid-19. Accessed om 30 July 2020.

38. FurutaY, Gowen BB, Takahashi K,Shiraki K, Smee DF, and Barnard D. L. Favipiravir (T-705), a novel viral RNA polymerase inhibitor. Antiviral Res. 2013;100:446-54.

39. Clinicaltrials.Gov (20201). Clinical Study to Evaluate the Performance And Safety of Favipiravir in COVID19. Available at: https://clinicaltrials.gov/ct2/show/ NCT04336904. Accessed on 08 April 2020.

40. Westover JB, Mathis A, Taylor R, Wandersee L, Bailey K W, Sefing E J et al. Galidesivir limits Rift Valley fever virus infection and disease in Syrian golden hamsters. Antiviral Res. 2018;156:38-45.

41. Clinicaltrials.Gov (2020bp). A Study to Evaluate the Safety, Pharmacokinetics and Antiviral Effects of Galidesivir in Yellow Fever or COVID-19. Available at: https://clinicaltrials.gov/ct2/show/NCT03891420 Accessed on 15 April 2020.

42. Barragan P, Podzamczer D. Lopinavir/ritonavir: a protease inhibitor for HIV-1 treatment. Expert Opin Pharmacother. 2008;9:2363-75.

43. Clinicaltrials. Gov (2020ak). Evaluating and Comparing the Safety and Efficiency of 
ASC09/Ritonavir and Lopinavir/Ritonavir for Novel Coronavirus Infection. Available at: https://clinicaltrials.gov/ct2/show/NCT04261907. Accessed on 10 February 2020.

44. Chen H, Zhang Z, Wang L, Huang Z, Gong F, Li X et al. (2020). First Clinical Study Using HCV Protease Inhibitor Danoprevir to Treat Naive and Experienced COVID-19 Patients. Med Rxiv. 2020.2003.2022.20034041.

45. Campbell WC, Fisher MH, Stapley EO, AlbersSchönberg G, Jacob TA, Ivermectin. A potent new antiparasitic agent. Science 1983;221:823-28.

46. Clinicaltrials. Gov (2020bv). Trial to Promote Recovery from COVID-19 with Ivermectin or Endocrine Therapy (RECOVER). Available at: https:// clinicaltrials.gov/ct2/show/NCT04374279 (Accessed on 05 May 2020.

47. Hemady RK, Sinibaldi VJ andEisenberger MA. Ocular symptoms and signs associated with suramin sodium treatment for metastatic cancer of the prostate. Am J Ophthalmol. 1996;121:291-6.

48. Chictr. Org.Cn (2020d). A multi-center study on the efficacy and safety of suramin sodium in adult patients with novel coronavirus pneumonia (COVID-19). Available at: http://www.chictr.org.cn/showprojen.aspx ?proj=4982 4. Accessed on 21 February 2020.

49. Dunn CJ and Barradell LB. Azithromycin. Drugs 1996;51:483-505.

50. Mohammad FS, Karmakar V, and Irfan. Z. Hydroxychloroquine and azithromycin combination could be lethal to covid-19 patients. Farmacia 2020;68(3):384-9.

51. Sargiacomo C, Sotgia F, and Lisanti MP. COVID-19 and chronological aging: senolytics and other antiaging drugs for the treatment or prevention of corona virus infection? Aging. 2020;12:6511-17.

52. Clinicaltrials.Gov (2020y). DYNAMIC Study (DoxycYcliNeAMbulatoIre COVID19) (DYNAMIC). Available at: https://clinicaltrials.gov/ct2/show/ NCT04371952. Accessed on 07 May 2020.

53. Claman HN Corticosteroids and Lymphoid Cells. New Engl J Med. 1972;287:388-97.

54. Russell CD, Millar JE, and Baillie JK. Clinical evidence does not support corticosteroid treatment for 2019-nCoV lung injury. Lancet. 2020;395:473- 5.

55. Chun $\mathbf{J}$ and Hartung (H P.). Mechanism of action of oral fingolimod (FTY720) in multiple sclerosis. Clin Neuropharmacol. 2010;33:91-101.

56. Clinicaltrials.Gov (2020al). Fingolimod in COVID19. Available at: https:// clinicaltrials.gov/ct2/show/NCT04280588. Accessed on 21 February 2020.

57. Shannon E, Noveck R, Sandoval F, and Kamath B. Thalidomide suppressed IL-1beta while enhancing TNF-alpha and IL-10, when cells in whole blood were stimulated with lipopolysaccharide. Immunopharmacol Immunotoxicol 2008;30:447-57.
58. Clinicaltrials.Gov (2020ac). The Efficacy and Safety of Thalidomide in the Adjuvant Treatment of Moderate New Coronavirus (COVID-19) Pneumonia. Available

https://clinicaltrials.gov/ct2/show/NCT04273529

Accessed on 21 February 2020.

59. Rozman B. Clinical Pharmacokinetics of Leflunomide. Clin Pharmacokinet 2002;41:421-30.

60. Clinicaltrials.Gov (2020ar). Leflunomide in Mild COVID-19 Patients. Available at: https://clinicaltrials.gov/ct2/show/NCT04361214 Accessed on 11 May 2020.

61. Clinicaltrials.Gov (2020m). Colchicine Coronavirus SARS-CoV2 Trial (COLCORONA) (COVID-19). Available at: https://clinicaltrials.gov/ct2/show/ NCT04322682. Accessed on 24 April 2020.

62. Clinicaltrials.Gov (2020as). LIBERATE Trial in COVID-19 (LIBERATE). Available at: https://clinicaltrials.gov/ct2/show/NCT04334629. Accessed on 01 May 2020.

63. Clinicaltrials.Gov (2020ae). Efficacy of Addition of Naproxen in the Treatment of Critically Ill Patients Hospitalized for COVID-19 Infection (ENACOVID). Available https://clinicaltrials.gov/ct2/show/NCT04325633 Accessed on 14 April 2020.

64. Clinicaltrials.Gov (2020ap). Jaktinib Dihydrochloride Monohydrate in Idiopathic Pulmonary Fibrosis. Available at: https://clinicaltrials.gov/ct2/show/ NCT04312594. Accessed on 30 April 2020.

65. Clinicaltrials.Gov (2020ax). Phase 3 Randomized, Double-blind, Placebo-controlled Multicenter Study to Assess the Efficacy and Safety of Ruxolitinib in Patients with COVID-19 Associated Cytokine Storm (RUXCOVID) (RUXCOVID). Available at: https:/clinicaltrials.gov/ct2/show/NCT04362137. Accessed on 07 May 2020.

66. Clinicaltrials.Gov (2020f). Baricitinib in Symptomatic Patients Infected by COVID19: an Open-label, Pilot Study. Available at: https://clinicaltrials.gov/ct2/show/ NCT04320277 Accessed on 22 April 2020.

67. Clinicaltrials.Gov (2020bs). TOFAcitinib in SARSCoV2 Pneumonia. Available at: https://clinicaltrials.gov/ct2/show/NCT0433204. (Accessed on 02 April 2020.

68. Ying W, QianY, and Kun Z. Drugs supply and pharmaceutical care management practices at a designated hospital during the COVID-19 epidemic. Res Soc Administrative Pharm 2020; 1520:30325-9.

69. Chictr.Org.Cn (2020c). Efficacy and safety of tozumab combined with adamumab (Qletli) in severe and critical patients with novel coronavirus pneumonia (COVID-19). Available at: http://www.chictr.org.cn/showprojen.aspx?proj= 50693. Accessed on 15 March 2020.

70. Röth A, Rottinghaus ST, Hill A, Bachman ES, Kim JS, Schrezenmeier H et al. Ravulizumab (ALXN1210) in patients with paroxysmal nocturnal hemoglobinuria: 
results of 2 phase 1b/2 studies. Blood Adv. 2018;2: 2176-85.

71. Clinicaltrials.Gov (2020ad). Efficacy and Safety Study of IV Ravulizumab in Patients with COVID-19 Severe Pneumonia. Available at: https://clinicaltrials. gov/ct2/show/NCT04369469. Accessed on 30 April 2020.

72. Clinicaltrials.Gov (2020bo). Study to Evaluate the Efficacy and Safety of Leronlimab for Patients with Severe or Critical Coronavirus Disease 2019 (COVID19). Available https://clinicaltrials.gov/ct2/show/NCT04347239. Accessed on 01 May 2020.

73. Le, RQ, Li L, Yuan W, Shord SS, Nie L, Habtemariam BA et al. FDA Approval Summary: Tocilizumab for Treatment of Chimeric Antigen Receptor T CellInduced Severe or Life-Threatening Cytokine Release Syndrome. Oncologist. 2018;23:943-7.

74. Clinicaltrials.Gov (2020br). Tocilizumab in the Treatment of Coronavirus Induced Disease (COVID19) (CORON-ACT). Available at: https://clinicaltrials.gov/ct2/show/NCT04335071. Accessed on 28 April 2020.

75. Shakoory B, Carcillo JA, Chatham WW, Amdur RL, Zhao H, Dinarello CA. Interleukin-1 Receptor Blockade Is Associated With Reduced Mortality in Sepsis Patients With Features of Macrophage Activation Syndrome: Reanalysis of a Prior Phase III Trial. Crit Care Med. 2016;44(2):275-81.

76. Huet $\mathrm{T}$, Beaussier $\mathrm{H}$, Voisin O, Jouveshomme S, Dauriat G, Lazareth I et.al. Anakinra for severe forms of COVID-19: a cohort study. Lancet Rheumatol 2020;2:e393-400.

77. Abassi ZA, Skorecki K, Heyman SN, Kinaneh S, Armaly Z. Covid-19 infection and mortality - A physiologist's perspective enlightening clinical features and plausible interventional strategies. Am J Phys Lung Cell Mol Physiol. 2020;318(5):1020L1022.

78. Clinicaltrials.Gov (2020bf). Randomized, Embedded, Multifactorial Adaptive Platform Trial for Community- Acquired Pneumonia (REMAP-CAP).
Available at: https://clinicaltrials.gov/ct2/show /NCT02735707 Accessed on 16 April 2020.

79. Meng J, Xiao G, Zhang J, He X, Ou M, Jing B. et al. Renin-angiotensin system inhibitors improve the clinical outcomes of COVID-19 patients with hypertension. Emerg Microbes Infect 2020;9(1):757760.

80. Rojas M, Rodriguez Y, Monsalve DM, AcostaAmpudia Y, Camacho B, Gallo JE, et al. Convalescent plasma in Covid-19: Possible mechanisms of action. Autoimmun Rev. 2020;19(7):102554.

81. May, JM, and Harrison, FE. Role of vitamin C in the function of the vascular endothelium. Antioxid. Redox Signal. 2013; 19: 2068-83.

82. Wilson JX. Evaluation of vitamin C for adjuvant sepsis therapy. Antioxid Redox Signal. 2013;19: 2129-40.

83. Clinicaltrials.Gov (2020c). Administration of Intravenous Vitamin C in Novel Coronavirus Infection (COVID-19) and Decreased Oxygenation (AVoCaDO). Available at: https://clinicaltrials.gov/ct2/show/NCT04357782. Accessed on 22 April 2020.

84. Clinicaltrials.Gov (2020aq). The LEAD COVID-19 Trial: Low-risk, Early Aspirin and Vitamin D to Reduce COVID-19 Hospitalizations (LEAD COVID19). Available at: https://clinicaltrials.gov/ct2/show/NCT04363840. Accessed on 06 May 2020.

85. Clinicaltrials.Gov (2020x). COvid-19 and Vitamin D Supplementation: a Multicenter Randomized Controlled Trial of High Dose Versus Standard Dose Vitamin D3 in Highrisk COVID-19 Patients (CoVitTrial). Available at: https:// clinicaltrials.gov/ct2/show/NCT04344041. Accessed on 06 May 2020.

Cite this article as: Khan SA, Siddiqui NI. Pathophysiology of COVID-19 and its potential therapeutics. Int J Basic Clin Pharmacol 2021;10:201-8. 